Nigel L.P. Symons mB BS FFARACS, Alick F.T. Hobbes MB BS B SCMED FFARACS, Hal K. Leaver MB BS

\title{
Anaphylactoid reac- tions to vancomycin during anaesthesia: two clinical reports
}

Vancomycin is becoming increasingly used for prophylaxis, and treatment against resistant forms of penicillinase-producing staphylococci. This drug, and the aminoglycosides as a group, have serious side-effects and organ toxicity, and may interact with anaesthetic drugs, particularly muscle relaxants. Two cases of anaphylactoid reactions to vancomycin are reported. The first patient subsequently developed oliguria and marked oedema, while the second developed non-cardiogenic pulmonary oedema.

\section{Key words}

ANAESTHESIA: vascular; COMPLICATIONS: anaphylactoid reactions, pulmonary oedema; ANTIBIOTICs: vancomycin.

Vancomycin, and the aminoglycosides as a group, have potentially serious side effects and organ toxicity. ${ }^{l-3}$ Vancomycin may cause fever, pain on injection or phlebitis, nephrotoxicity or ototoxicity and depression of myocardial function. ${ }^{3,4}$ Anaphylactic or anaphylactoid reactions are well documented $^{5,6}$ and may be life-threatening if occurring during anaesthesia or surgery. Two cases are reported where cardiovascular collapse occurred following infusion of vancomycin. Bronchospasm was not a feature of these or a previous report. Both patients demonstrated a continuing problem with

From the Department of Anaesthesia, Royal North Shore Hospital of Sydney, St. Leonards, N.S.W., Australia.

Address correspondence to: Dr. N.L.P. Symons, Department of Anaesthesia, The Montreal General Hospital, 1650 Cedar Avenue, Montreal, Quebec, Canada H3G 1A4. capillary leakage, for up to 48 hours following anaphlyactoid reaction to vancomycin.

\section{Report of two cases}

\section{Patient one}

A 71-year-old woman was scheduled for an aortobifemoral bypass graft. She had previously undergone a right femoral-politeal bypass and lumbar sympathectomy with no documented anaesthetic problems. She had no known allergies and no previous exposure to vancomycin.

Preoperative chest $x$-ray and electrocardiogram were normal. There was no evidence of cardiac failure. Blood pressure was $150 / 70 \mathrm{mmHg}$. Her haemoglobin was $142 \mathrm{gm} \cdot \mathrm{L}^{-1}$ and serum electrolytes, creatinine, urea and albumin were in the normal range.

Diazepam $10 \mathrm{mg}$ was administered orally on the morning of surgery, and peripheral venous, central venous (CVP) and arterial lines inserted prior to induction. Infusions of Ringer's Lactate solution and 20 per cent mannitol were commenced.

The patient was anaesthetized with fentanyl 5 $\mu \mathrm{g} \cdot \mathrm{kg}^{-1}$, thiopentone $75 \mathrm{mg}$ and pancuronium $6 \mathrm{mg}$, intubated and ventilated with oxygen 30 per cent and nitrous oxide with enflurane $0.2-0.4$ per cent to maintain systolic arterial pressure (SAP) at $140 \mathrm{mmHg}$.

Twenty minutes after induction, and prior to aortic clamping, vancomycin $500 \mathrm{mg}$ in $100 \mathrm{ml}$ five per cent dextrose was commenced to run over 20 minutes. After six minutes the patient developed intense truncal and facial erythema, which progressed to maximal intensity over one minute. SAP fell to 40 $\mathrm{mmHg}$. The vancomycin was immediately stopped (after approximately $150 \mathrm{mg}$ had been infused). There was no bronchospasm. Ventilation with 100 
per cent oxygen was commenced, the patient was placed head down and infusion of SPPS (Stabilized Plasma Protein Solution, equivalent to five per cent albumin) commenced. The patient received metaraminol $7.5 \mathrm{mg}$ IV in increments and $100 \mathrm{mg}$ hydrocortisone IV. The SAP rapidly rose to 100 $\mathrm{mmHg}$ and then slowly to $130 \mathrm{mmHg}$ over the next ten minutes. Her CVP remained constant at $10 \mathrm{~cm}$ $\mathrm{H}_{2} \mathrm{O}$ despite the rapid infusion of $1000 \mathrm{ml}$ SPPS. The completion of the anaesthetic and operation was uneventful.

Large volumes of colloid $(1500 \mathrm{ml})$ and crystalloid $(2500 \mathrm{ml})$ were required during the next 16 hours to maintain CVP at $8-10 \mathrm{~cm} \mathrm{H}_{2} \mathrm{O}$. Urine output remained at $20-30 \mathrm{ml} \cdot \mathrm{hr}^{-1}$. She developed marked peri-orbital, sacral and peripheral oedema. The serum albumin fell from 42 to $30 \mathrm{gm} \cdot \mathrm{L}^{-1}$ and total protein from 70 to $55 \mathrm{gm} \cdot \mathrm{L}^{-1}$ despite $2500 \mathrm{ml}$ of SPPS. Forty-eight hours postoperatively the urine output abruptly improved and the oedema rapidly resolved. Serum albumin rose to $38 \mathrm{gm}^{-1}$. She was discharged from the intensive care unit. Her further recovery was uneventful.

\section{Patient two}

An 80-year-old male presented with a pulsatile mass in his left groin. Abdominal ultrasound revealed an $8 \mathrm{~cm}$ aneurysm of the lower abdominal aorta extending into both common iliac arteries. He had a history of hypertension, treated with propranolol. There were no known allergies, no previously documented anaesthetic problems, and no previous exposure to vancomycin. Physical examination was unremarkable, and chest $x$-ray was normal. However, his electrocardiogram showed signs of left ventricular hypertrophy. Preoperative haemoglobin was $106 \mathrm{gm} \cdot \mathrm{L}^{-1}$ and haematocrit 34.0 per cent. Serum creatinine was mildly elevated at $0.18 \mathrm{mmol} \cdot \mathrm{L}^{-1}$. Serum electrolytes, albumin and total protein were in the normal range.

The patient was premedicated with diazepam 10 mg orally. Peripheral venous, CVP and arterial lines were inserted and anaesthesia induced with fentanyl $8 \mu \mathrm{g} \cdot \mathrm{kg}^{-1}$, thiopentone $50 \mathrm{mg}$ and pancuronium $8 \mathrm{mg}$. Anaesthesia was maintained with 40 per cent oxygen and nitrous oxide and enflurane introduced to keep SAP at $150 \mathrm{mmHg}$. Arterial blood gases (ABG) after induction revealed $\mathrm{pH} 7.43, \mathrm{PCO}_{2} 34$ $\mathrm{mmHg}$ and $\mathrm{PO}_{2} 113 \mathrm{mmHg}$. An infusion of vancomycin $500 \mathrm{mg}$ in $100 \mathrm{ml}$ five per cent dextrose was commenced to run over 30 minutes. After approximately ten minutes an intense truncal and facial erythema developed, SAP fell to $25 \mathrm{mmHg}$, heart rate remained $90 / \mathrm{min}$ but electrocardiogram showed T-segment depression of $2 \mathrm{~mm}$. The vancomycin infusion was stopped (after total dose of $180 \mathrm{mg}$ ), patient placed head down and ventilated with 100 per cent oxygen. Ringer's Lactate solution $500 \mathrm{ml}$, SPPS $500 \mathrm{ml}$ and metaraminol $6 \mathrm{mg} \mathrm{IV}$ in increments over $4 \mathrm{~min}$ returned the SAP to $120 \mathrm{mmHg}$ and ST-segments to an iso-electric position. CVP remained constant at $8 \mathrm{~cm} \mathrm{H}_{2} \mathrm{O}$. The erythema faded over the next $15 \mathrm{~min}$, and the operation proceeded. $A B G$ 's taken after the aortic clamp was released showed $\mathrm{pH} 7.38, \mathrm{PCO}_{2} 33 \mathrm{mmHg}$ and $\mathrm{PO}_{2}$ $119 \mathrm{mmHg}\left(\mathrm{FIO}_{2} 0.40\right)$. Blood pressure and CVP were stable and the patient was transferred to the intensive care unit.

Over the next two hours the patient became peripherally vasoconstricted and cyanosed. Blood pressure was $140 / 90 \mathrm{mmHg}$, CVP remained $8-10 \mathrm{~cm}$ $\mathrm{H}_{2} \mathrm{O}$. A pulmonary artery catheter inserted in the intensive care unit showed the pulmonary capillary wedge pressure was $14 \mathrm{~cm} \mathrm{H} \mathrm{H}_{2} \mathrm{O}$. ABG's $\left(\mathrm{FIO}_{2} 0.8\right)$ were $\mathrm{pH} 7.27, \mathrm{PCO}_{2} 58 \mathrm{mmHg}$ and $\mathrm{PO}_{2} 38 \mathrm{mmHg}$. The chest $x$-ray showed bilateral alveolar pulmonary oedema. Serum albumin had fallen from 41 to 34 $\mathrm{gm} \cdot \mathrm{L}^{-1}$, and haemoglobin had risen to $148 \mathrm{gm} \cdot \mathrm{L}^{-1}$ with a haematocrit of 43 per cent. The electrocardiogram was unchanged. The acute respiratory failure responded to ventilation with PEEP, and infusions of both adrenalin and nitroprusside. The patient's condition rapidly improved and extubation took place two days later. The serum albumin had fallen to a low of $32 \mathrm{gm} \cdot \mathrm{L}^{-1}$ on the second postoperative day, despite a further $1200 \mathrm{ml}$ of SPPS on day one and a further $700 \mathrm{ml}$ on day two. This patient subsequently had intradermal skin testing performed for all drugs used during the course of his anaesthetic. He was strongly positive only for vancomycin.

\section{Discussion}

Vancomycin is an aminoglycoside antibiotic, produced from a microorganism found in a soil sample from the "jungle trails of Borneo." There has been a recent resurgence in its use against staphylococcal infections. It is of particular use where: infection is caused by methicillin-resistant or penicillinaseproducing staphylococci; infections caused by 
diptheroids; prophylaxis of bacterial endocarditis; penicillin allergy; staphylococcal infections in patients undergoing renal dialysis; and staphylococcal enterocolitis. $^{2}$

Complications from therapy with vancomycin include fever, phlebitis, pain at the injection site, macular skin rashes, eosinophilia, ototoxicity, nephrotoxicity and possible depression of myocardial function. ${ }^{2-4}$ Anaphylaxis has been reported. ${ }^{5,6}$ Depression of myocardial function was reported in a retrospective study ${ }^{4}$ where 11 of 76 patients had a fall in systolic blood pressure of up to 50 per cent following rapid infusion of vancomycin. This was felt to be a primary depressant action of vancomycin on the myocardium. The mechanism was unknown. Cohen et al. ${ }^{3}$ found that in intact dogs and in isolated muscle preparations that vancomycin produced a depression of myocardial function as well as a mean decrease of 30 per cent in vascular resistance.

Anaphylaxis during anaesthesia, and the diagnosis and management have been reported. ${ }^{7-10}$ Anaphylactoid reactions to vancomycin during anaesthesia has also been reported. ${ }^{6}$ Both this case and the two described here were characterized by life-threatening cardiovascular collapse and erythematous rash occurring soon after the intravenous administration of the drug. In none of the cases described was bronchospasm a feature. All three cases responded rapidly to the cessation of vancomycin, the use of head-down positioning and intravenous administration of fluids and vasopressor agents. To our knowledge, however, no one has yet documented a continuing increase in systemic and pulmonary capillary permeability with vancomycin, although these problems could be expected following severe anaphylactoid reactions. ${ }^{7-9}$

An anaphylactoid reaction is due to a direct effect of the drug on mast cells and basophils that stimulate the release of histamine. The manifestations of an anaphylactoid reaction are indistinguishable from anaphylaxis (type one hypersensitivity) and compliment activation; however, the histamine release is not dependent on prior exposure or presence of antibodies to the drug involved. ${ }^{7,10}$

The manifestation of an allergic reaction may vary widely in different people. The most common are skin changes, hypotension and tachycardia. Bronchospasm is the most life-threatening feature of an allergic reaction. ${ }^{10}$ Treatment must be aimed at: (a) correcting hypoxaemia; (b) restoring intravascular blood volume and perfusion pressure; and (c) blocking the further release of chemical mediators (histamine, SRS-A, serotonin and complement). While most of the features of anaphylaxis may be produced by histamine alone, a complex system of mediators is involved. The mediators affect target organs by producing a fall in cyclic 3,5-AMP. Epinephrine is believed to increase levels of c-AMP and thereby inhibit degranulation and further release of histamine. Both our patients responded rapidly to colloid infusions and metarminol, therefore epinephrine was withheld, although in retrospect it may have prevented the problems encountered due to ongoing increase in capillary permeability.

In the first case described the permeability changes were manifest by periorbital, sacral and peripheral oedema, oliguria and hypoalbuminaemia, despite the infusion of albumin containing solutions. There was spontaneous recovery in 48 hours. The second patient demonstrated a fall in serum proteins, haemoconcentration and non-cardiogenic pulmonary oedema, which responded to ventilation with PEEP, and use of epinephrine

While anaphylactic reactions during anaesthesia may occur at any time during the perioperative period, most reactions occur during induction. ${ }^{7}$ In a study of 116 patients Fisher $e t$ al. found that 112 occurred within $3 \mathrm{~min}$ of drug administration. All the reported cases of reaction to vancomycin occurred within $30 \mathrm{~min}$, most within $10 \mathrm{~min}$ from commencement of infusion.

The use of other drugs in the treatment of anaphylactic/anaphylactoid reaction is controversial. Some authors feel that the administration of $\mathrm{H}_{1}$ and $\mathrm{H}_{2}$ antagonists may be beneficial both for treatment and prophylaxis ${ }^{10-12}$ and may be combined with corticosteroids.

Confirmation of anaphylactoid reaction to a specific drug may be possible using intradermal skin testing $7,8,10,11$ where a specific drug or drugs are injected $(0.1 \mathrm{ml}$ of a $1: 1000$ dilution or less). Only one of the two patients was able to be tested, and he was strongly positive only for vancomycin. Confirmation of anaphylactic reaction is usually based on history of previous response or reaction to a drug and serial laboratory measurements of $\operatorname{IgE}$ antibodies and complement proteins $\mathrm{C}_{3}$ and $\mathrm{C}_{4}$ during the 72 hours after an adverse response. ${ }^{10}$

In summary, major reactions can occur to vanco- 
mycin both as a result of rapid infusion of the drug producing myocardial depression and peripheral vasodilation; and anaphylactoid reactions may occur which may take $10-30 \mathrm{~min}$ to develop and require both immediate resuscitation as well as ongoing treatment.

\section{References}

1 Griffith RS. Introduction to vancomycin. Rev Infect Dis 1981; 3: (Suppl) S200-4.

2 Cook. FV, Farrar WE. Vancomycin revisited. Ann Int Med 1978; 88: 813-8.

3 Cohen LS, Weschler AS, Mitchell JH, Glick, G. Depression of cardiac function by streptomycin and other antimicrobial agents. Am J Cardiol 1970; 26: 505-11.

4 Newfield P. Poizer MF. Hazards of rapid administration of vancomycin. Ann Int Med 1979; 91 : 581.

5 Rothenburg $M J$. Anaphylactoid reaction to vancomycin. J Am Med Assoc 1959; 171: 123-4.

6 Miller $R$, Tausk $H C$. Anaphylactoid reaction to vancomycin during anaesthesia: a case report. Anesth Analg 1977; 56: 870-2.

7 Fisher $M M C D$. Severe histamine mediate reactions to intravenous drugs used in anaesthesia. Anaesth Intensive Care 1975; 3: 180-91.

8 Fisher $M M C D$, More $D G$. The epidemiology and clinical features of anaphylactic reactions in anaesthesia. Anaesth Intensive Care 1981; 9: 223-6.

9 Fisher $M M C D$. Blood volume replacement in acute anaphylactic cardiovascular collapse related to anaesthesia. Br J Anaesth 1977; 49: 1023-6.

10 Stoetling $R K$. Allergic reactions during anaesthesia. Anesth Analg 1983; 62: 341-56.

11 Fisher $M M C D$. The diagnosis of acute anaphylactoid reactions to anaesthetic drugs. Anaesth Intensive Care 1981; 9: 235-41.

12 Moss J, McDermott DJ, Thisted RA, Roizen MF, Smith WS. Anaphylactic/anaphylactoid reactions in response to chymodactin (chymopapain). Anesth Analg 1983; 63: 253. Abstract.

\section{Résumé}

La vancomycin est de plus en plus employée comme agent prophylactique et thérapeutique contre les formes résistantes de staphylocoques produisant la pénicillinase. Cette drogue, ainsi que les aminosides comme groupe. présente des effets secondaires sérieux ainsi qu'une toxicité organique el peut interagir avec les médicamens anesthésiques, plus particulièrement les relaxants musculaires. Delux cas de réaction anaphylactoide à la vancomycin sont rapportés. Le premier patient a développé subséquemment une oligurie et un oedème marqué alors que le second a développé un oedème pulmonaire non-cardiogénique. 